\title{
Studies of Structural Changes in Surface and Deep Layers in Magnetite Crystals After High Pressure Pressing
}

\author{
P. Matyukhin ${ }^{(凶)}$ \\ Belgorod State Technical University named after V.G. Shukhov, \\ Belgorod, Russia \\ mpvbgtu@mail.ru
}

\begin{abstract}
The article introduces the study of structural changes in surface and deep layers in magnetite crystals, on samples under high pressure pressing. Magnetite (magnetite iron-ore concentrate) is widely used as a filling compound of new composites which are planned to be used in nuclear-construction. These compounds are based on the aluminum containing matrix with a filling compound. This modern composite material can be used in construction structures able to resist significant loads, operate in such extreme situations as abrupt dynamic loads, fires with further alternating temperature oscillations.
\end{abstract}

Keywords: Magnetite $\cdot$ Pressure $\cdot$ Crystal $\cdot$ Structure $\cdot$ Layer $\cdot$ Material

\section{Introduction}

Nowadays many scientists develop new kinds of materials, including composites which can be used in nearly all spheres of human life. Composite materials based on organic and inorganic components with different additives and fillers are created. These components can be the base for different matrixes. Fillers with different qualities are introduced into these matrixes depending on the purpose, scope of operation, conditions of service of the designed composite. These matrixes can have metal, ceramics, concrete, polymer and other bases, and the fillers may be cast iron shot, barites, metal processing remains, mining company products (for example, iron containing rocks) and of other enterprises (Grishina and Korolev 2016; Barabash et al. 2017; Matyukhin 2018; Gulbin et al. 2018; Kruglova 2009; Laptev et al. 2015; Gulbin et al. 2016; Matyukhin et al. 2011, Samoshin et al. 2017).

Composite materials based on metal matrixes can be used in bearing constructions production. Such constructions can resist high mechanical impacts, intensive ionizing radiation and alternating temperatures, that can widely be used in nuclear construction industry, and foremost, for biological protection on sites with power supplies of different nature. Nowadays, the issue of aluminum containing matrixes and iron containing fillers utilization in designing new types of radiation-protective construction composite materials becomes acute. One of promising fillers for new composite 
materials is magnetite. The introduction of modern composite materials of natural iron ore raw materials will give them additional mechanical strength, increase their radiation shielding characteristics. This filler is widely found in nature, is relatively cheap, and composites on its base will meet ecological requirements as they are a part of the ecosystem. Here a possibility of combining magnetite iron ore concentrate with aluminum containing matrix and receiving composite material by high pressure pressing is of great scientific interest. In this research it is necessary to solve issues about maximum possible filler compacting in its composite material matrix, studying composite filler behaviour at high pressing pressures, in particular studying structural changes in surface and deep layers of magnetite crystals at pressing pressures when such a composite material is produced, and compact-space position of its particles relative to each other.

\section{Methods and Approaches}

As an object of research we used a highly-dispersive enriched magnetite iron-ore concentrate from the Lebedinsk deposit of the Kursk Magnetic Anomaly with density $4950 \mathrm{~kg} / \mathrm{m}^{3}$, Mohs hardness - 6, black colour; the magnetite is in form of irregular needle-shaped grains, octahedral crystals, shell-like fracture; the mineral composition is introduced by magnetite with inclusions of carbonate (chalk-stone) and siliceous (quartz) admixtures. After cleaning and chemical treatment of the magnetite iron ore concentrate per $99,8 \%$ its mineral composition is introduced by magnetite $\left(\mathrm{FeO} . \mathrm{Fe}_{2} \mathrm{O}_{3}\right)$ with fractional composition of particles $0,05-15 \mathrm{mcm}$. In the research we used a modern electronic microscope "TESCAN MIRA 3 LMU".

\section{Results and Discussion}

For experiment fairness the magnetite samples in the form of a high dispersive powder with particles $0,05-15 \mathrm{mcm}$ were used, without adding it into the aluminium containing matrix. Figure 1 shows the structure of surface and deep layers of magnetite particles without pressure treatment (Fig. 1a) and after pressure pressing $5000 \mathrm{MPa}$ (Fig. 1b) with magnifying power $10 \mathrm{mcm}$. The analysis of the received data showed that the surface and deep layers of magnetite crystal particles after pressure pressing at $5000 \mathrm{MPa}$ (Fig. 1b), in comparison with the micro photo of magnetite crystal particles not pressed (Fig. 1a), there are spaces with loose distribution of its particles along the whole sample volume: there are numerous empty spaces; particles have irregular form with hard aggregation and rough edges. Figure 2 shows the structure of surface and deep magnetite particle layers, after pressure $10000 \mathrm{MPa}$ and $20000 \mathrm{MPa}$ with magnifying power $10 \mathrm{mcm}$. 


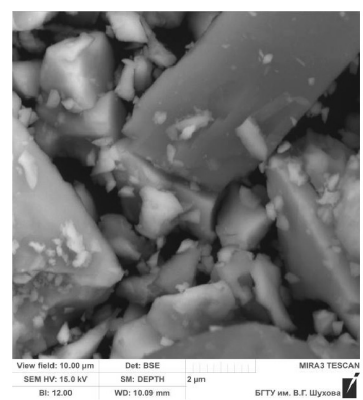

a)

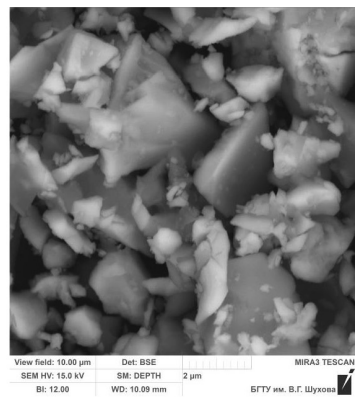

b)

Fig. 1. Magnetite surface with magnifying power $10 \mathrm{mcm}$ : (a) without pressure pressing treatment, $(b)$ after pressure treatment $5000 \mathrm{MPa}$

The received data analysis showed that at pressure pressing increase up to $10000 \mathrm{MPa}$ (Fig. 2a) magnetite crystal particles were distributed more compactly within the whole volume of the studied sample: also there are numerous empty spaces but with a slight reduction of their geometrical sizes; the magnetite particles structure changed insignificantly, as before they had irregular form with strong aggregation and rough edges, but here particles of smaller fraction appeared, that evidenced the process of partial mechanical destruction of its particles.

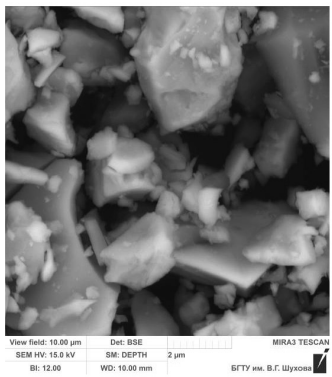

a)

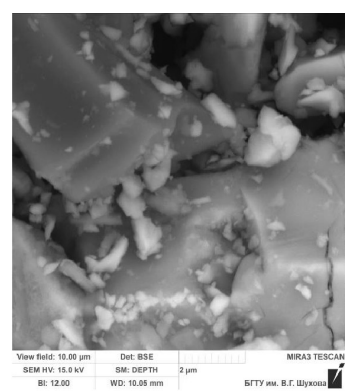

b)

Fig. 2. Magnetite surface with magnifying power $10 \mathrm{mcm}$ : (a) after pressure pressing $10000 \mathrm{MPa},(b)$ after pressure pressing $20000 \mathrm{MPa}$

When the pressure increases up to $20000 \mathrm{MPa}$ on the magnetite crystal particles (Fig. 2b), there is a more compact visual magnetite particle packing both in surface and deep layers of the studied sample; there is a significant increase of zones with good compaction. There is a greater degree of destruction of magnetite crystal particles surface in the total amount of material samples in comparison with previous pressure pressing; somewhere surface aggregation and hematite particles edges is smoothed. 
It evidences qualitative distribution of hematite particles of all fraction composition along the whole sample volume, but micro photos show remaining zones with "insufficient compaction", where there is a lack of fine-fractioned magnetite particles.

\section{Conclusions}

Based on the studies of structure changes in surface and deep layers of magnetite crystals, after high pressure pressing and studied with electron microscope, we can make an assumption that the structure of the composite may be denser by adding magnetite into its filler 15-25\% (by volume) of its particles, but smaller fraction in comparison the studied one. It is theoretically possible that after adding such an amount of magnetite fine-fraction a higher degree of sample material compacting will be achieved. Or to conduct the studies with adding the same percentage ratio into the volume of studied composite material matrix samples in the form of aluminum powder, as it has particles less in size than magnetite particles. We think that these studies have high theoretical and practical significance and they should be taken into account when developing new composite materials based on magnetite filler and different metal matrixes.

Acknowledgements. The work is realized in the framework of the Program of flagship university development on the base of the Belgorod State Technological University named after V.G. Shukhov, using equipment of High Technology Center at BSTU named after V.G. Shukhov.

\section{References}

Barabash DE, Barabash AD, Potapov YuB, Panfilov DV, Perekalskiy OE (2017) Radiationresistant composite for biological shield of personnel. In: IOP conference series: earth and environmental science. C. 012085

Grishina AN, Korolev EV (2016) New radiation-protective binder for special-purpose composites. Key Eng Mater 683:318-324

Gulbin VN, Kolpakov NS, Gorkavenko VV, Boikov AA (2018) Research of the structure and properties of radio and radiation-protective polymer nanocomposites. J Electro-magnetic Waves Electron Syst 23(1):4-11

Gulbin VN, Martsenuk AV, Gorkavenko VV, Cherdyntsev VV (2016) Polymeric composites for radio and radio active protection. Sci Intensive Technol 17(10):7-12

Kruglova AN (2009) Radiation protective materials based on industrial wastes: physicmechanical properties. Reg Archit Const 1:53-56

Laptev GA, Potapov Y, Yerofeev VT (2015) Development of manufacturing technology metalloconcretes. Build Reconst 1(57):123-129

Matyukhin PV (2018) The choice of iron-containing filling for composite radioprotective material. In: IOP conference series: materials science and engineering 11. International conference on mechanical engineering, automation and control systems 2017 - material science in mechanical engineering. C. 032036

Matyukhin PV, Pavlenko VI, Yastrebinskiy RN, Bondarenko YuM, (2011) Prospects of creating modern highly constructive radiation-protective metalocomposites. Bulletin of BSTU named after V.G. Shukhov. 2, 97 
Ochkina NA (2018) Heat stability of radio-protective composite based on aluminous cement and polymineral industrial waste. Pridneprov Sci Bull 3(2):007-010

Samoshin AP, Korolev YV, Samoshina YN (2017) Internal stresses at metal concrete structure formation for protection from radiation. Bull. BSTU Named After V.G. Shukhov 6:13-17

Open Access This chapter is licensed under the terms of the Creative Commons Attribution 4.0 International License (http://creativecommons.org/licenses/by/4.0/), which permits use, sharing, adaptation, distribution and reproduction in any medium or format, as long as you give appropriate credit to the original author(s) and the source, provide a link to the Creative Commons license and indicate if changes were made.

The images or other third party material in this chapter are included in the chapter's Creative Commons license, unless indicated otherwise in a credit line to the material. If material is not included in the chapter's Creative Commons license and your intended use is not permitted by statutory regulation or exceeds the permitted use, you will need to obtain permission directly from the copyright holder. 